\title{
4
}

\section{The Roles and Impacts of the Third Sector in Europe}

\section{Bernard Enjolras and Karl Henrik Sivesind}

The development of social enterprises, social investment, social finance and new philanthropy (Salamon 2014a, b; Nicholls et al. 2010) has triggered an increasing focus on the measurement of the social value and social impact of the programs, operations and organizations of the third sector. Funders and policymakers want to know whether their funds and policies make a difference, and TSOs have been increasingly eager to be in a position to respond to these demands. More than that, as a distinctive set of organizations and behaviors, the third sector is regularly called upon to demonstrate that it generates social value that is distinctive, both in kind and quantity, from the other social sectors. In addition, since, in contrast to the corporation sector whose value is measured by market prices, the third sector lacks an automatic mechanism to document the benefits it generates, an array of valuation tools and measuring devices has had to be developed to accomplish this task.

B. Enjolras $(\bowtie) \bullet$ K. H. Sivesind

Institute for Social Research (ISF), Oslo, Norway

e-mail: bernard.enjolras@socialresearch.no;

karl.henrik.sivesind@socialresearch.no

(C) The Author(s) 2018

B. Enjolras et al., The Third Sector As A Renewable Resource for Europe, https://doi.org/10.1007/978-3-319-71473-8_4 
Most of the scholarly literature relative to the roles and functions of TSOs is related to the evaluation of impact at the organizational level, and is primarily concerned with the service function of TSOs. By contrast, systematic evidences of the impact of the third sector at the macro level and in relation to the sector's supposedly distinctive functions are lacking.

In this chapter, we seek to fill this gap, to shift the focus of impact assessment from the organizational level to the macro-sectoral level, to the third sector as a whole, asking, "What difference does the third sector make for society?" In doing so, moreover, we focus our attention not on the service functions of the sector but on certain distinctive functions of TSOs and volunteering compared to government, corporations and households. Included here are: the third sector's expressive role, allowing individuals and groups to freely express their values, interests and concerns in artistic, religious, cultural, ethnic, social, recreational and occupational areas; value guardian role, promoting freedom of speech, civil liberties or debates about norms and values as society changes; and advocacy role, providing links to the policymaking process for individuals, neighborhoods and different kinds of private interests. This civil society role is an essential part of a democratic society ruled by law because the legitimacy of political power relies on public discussions, hearings and consultations with affected groups. The TSE sector includes, among other things, voluntary associations and civic and advocacy organizations that have the potential for bridging multiple levels of governance. Given an open political culture, it represents an essential democratic infrastructure.

Measuring such impact is challenging, however. To find out if there is an impact of the third sector on society, we must answer the question, "What would have happened without the activity of third sector entities?" Many social scientific approaches can be used for this kind of counter-factual analysis, such as comparing changes over time before or after the third sector activity, comparing groups or countries that have experienced a certain third sector activity with those that have not, or using statistical methods that make it possible to control for the most important factors other than the third sector activity. It is particularly important to control for the effect of self-selection. People who volunteer for TSOs may already have characteristics that are assumed to be the result of their third sector involvement, such as a high level of civic engagement and sense of well-being. What is more, it is often difficult to differentiate between cause and effect. Countries that allow free expres- 
Third sector impact means, within the context of this chapter, direct or indirect, medium- to long-term consequences of the distinctive features of volunteering or of the third sector organizations on individuals or on the community, ranging from neighborhoods to society in general.

sion may be more conducive to the presence of TSOs. If that is so, it would be a mistake to attribute the openness to free expression to the third sector's presence.

Untangling these relationships and assessing the available information in light of them is the objective of this chapter. To do so, the chapter proceeds as follows. The first section starts by defining what different roles the third sector may play in society, and what indicators can potentially be used to tell if this activity results in impacts on other parts of society. In the second section, we look at some existing efforts to measure certain types of TSIs and assess what they can tell us about the actual impact that the third sector has. A third section then examines under what circumstances such impacts may be produced and what prevents them from emerging. Finally, we try to sum up what can be concluded from these various studies and assessments about the socioeconomic impact of the European third sector.

\section{Impact Areas}

The TSE sector has some characteristics that make it different from other parts of society consisting of corporations, the government and households. Based on these characteristics and the way TSOs are supposed to behave, we can state some hypotheses about the expected impact of these organizations and of the sector as a whole.

TSOs may be seen as fulfilling four functions or roles: economic, social, political and communicative. For each of these functions, it is also possible to differentiate the "mainstream" contribution of these organizations - that is, what TSO have in common with governmental and for-profit organizations-from their specific contribution-that is, 
the functional features that are especially characteristic or even exclusive to these organizations.

From an economic viewpoint, TSOs provide both goods and services, but also organize expressive activities in the domains of sport, culture, arts and so on. They mobilize voluntary resources_-voluntary work and donations - that are more difficult to mobilize, if not impossible, for other organizational forms. Additionally, they are most often oriented toward other ends than economic ends, even if in the pursuit of these ends they develop economic activities. From the political and communicative $^{1}$ perspectives, TSOs have the potential to constitute a counterpower to the state and economic powers, to act as schools of democracy and also constitute a communicative space where value contention is made possible. Being a space of associational life, TSOs have the capacity to promote and sustain norms and values of public interests and practices of civic engagement. They also have the potential to organize different types of identities and interests and to play a mediating and representative role in interacting with other societal spheres such as the state, the market or the family, influencing policies and attitudes. Being a communicative space, they have the capacity to enable debates, confrontations and contentions among individuals and organized actors animated by different values, interests and identities. By the play of these political and communicative functions, they contribute to the democratic infrastructure and might instigate social, axiological (valuebased) and political transformations impacting other societal spheres. From the social point of view, TSOs constitute a space of value pluralism and freedom and contribute to the maintenance of norms and values. From this viewpoint, the third sector is fundamental for enhancing and protecting the diversity of particular values, cultural practices and citizens' initiatives in all domains of social life. TSOs are also instrumental to the maintenance of norms and value that are more universal, such as those of solidarity, inclusion, trust and public interest. For this reason, they potentially have the capacity to contribute to the social integration of individuals and groups and to foster solidarity across differences.

\footnotetext{
${ }^{1}$ Insofar as third sector organizations are both constitutive and actors of the public sphere. The public sphere can be defined as comprising the institutional communicative spaces that facilitate public discussion and the formation of public opinion (see: Habermas 1989).
} 
For each of the roles played by TSOs, it is possible to infer a set of expected impacts at the individual, organizational, community and societal levels. Some of these impacts are likely to be distinctive (idiosyncratic) to TSOs, whereas other impacts can be common to those of other types of social actors. For example, if there were no TSE organizations with paid employment in social services funded by the government—such as institutions for elderly care—there probably would be public and for-profit providers performing those services. This is not to say that the social impacts of for-profit or government organizations providing the same services would be identical to those resulting from third sector provision, as TSOs, because of their distinctive features, innovate services in numerous fields, serve a more needy clientele, deliver services at a more human scale, stay in the game when government funding declines and so on. Hence, it is possible to differentiate the "mainstream" contributions of these organizations- that is, what TSOs have in common with governmental and for-profit organizations-from their distinctive contributions-that is, the functional features that are more characteristic, if not exclusive, to these organizations.

Based on reviews of previous research, these functions and roles can be translated into five domains of impact (Simsa et al. 2014; Enjolras 2015a, b):

- Well-being and quality of life

- Innovation

- Civic engagement, empowerment, advocacy and community building

- Economic impacts

- Human resources impacts

In the following section we will present some evidence of TSI based on analyses and reviews of research conducted by this project (on the basis of available data) related to the impact domains outlined above: civic engagement and advocacy; wellbeing and quality of life; human resources; and social innovation. However, as already stated, there are methodological problems related to previous research on impacts, and we address as far as possible these issues in our subsequent analysis. 


\section{Selected Evidence of TSIs}

\subsection{Some Methodological Challenges}

A review of the literature on TSIs on human resources and community by Kamerāde (2015) reveals the complexity of assessing the impact of the third sector at different levels. Indeed, impacts can be, first, assessed in terms of the consequences of voluntary participation for individuals involved in TSOs. The same literature review (Kamerāde 2015) concludes that evidence from a range of studies in different disciplinary fields suggests that the third sector makes an important impact; however, this impact is not equally accessible or widespread. The presence of TSOs is not an easy or straightforward solution for inequalities in participation and representation, or social integration problems, as their effects again vary between different social groups and types of organizations. This literature review highlights the unequal distribution of positive effects on individuals of participation in TSOs. More specifically, individuals who already have better wellbeing and health, and higher social trust, are more likely to be involved in the third sector, which, in turn, contributes to better health and wellbeing. In addition, individuals and groups who have fewer resources or who are already less advantaged in society are less likely to become involved in voluntary associations to promote their interests, satisfy their needs or make changes in policy favorable to them. Moreover, the effects of voluntary participation are gendered and can vary by age, employment status, income, type of association and type of involvement. In some cases, for particular groups, involvement in voluntary associations can have negative consequences.

This review points toward a major methodological issue plaguing TSI studies: many studies rely almost exclusively on analyses of cross-sectional data where volunteering and its hypothesized impact have been measured simultaneously. Although these studies provide valuable empirical evidence that is an important link in a chain of causal reasoning, in many of these studies, the causal relationships often have been assumed rather than demonstrated-in important part, because of the absence of data enabling the use of adequate methods for demonstrating the causal relationships. 
Furthermore, most of the studies on TSI have been conducted in a selected number of European countries, mainly in the UK, Netherlands, Germany, Norway, Belgium and the Czech Republic. Taking into account that the functions and extent of third sector involvement vary by social and institutional context, this raises the question of how far the impact findings from these institutional settings can be generalized across Europe and to other cultural and institutional contexts.

In spite of those methodological shortcomings, several studies of impact at both the individual and societal levels undertaken within the TSI project (based on available existing data) and outside it display mixed evidence about the impact of the third sector.

\subsection{Impact on Civic Engagement, Empowerment, Advocacy and Community Building}

Third sector organizations have long been viewed as arenas for civic and political participation and as schools for democracy (Almond and Verba 1963; Tocqueville 2000 [1835]). Closely related to this line of thinking is the emphasis recently placed on the third sector as a major contributor to social capital, to those bonds of trust and reciprocity without which neither democracy nor markets can operate (Putnam 1993, 2000). Howard and Gilbert (2008), for example, find empirical support for the Tocquevillian argument, according to which those persons with greater levels of involvement in voluntary organizations also engage in more political acts, have higher life satisfaction and are more trusting of others than those who do not. TSOs also are thought to play a central political role by channeling, articulating and advocating individuals' and groups' interests and values (Habermas 1998) and by participating in policy networks (Rhodes 1997) or advocacy coalitions (Sabatier 1998).

Political engagement and trust. As shown by Figs. 4.1 and 4.2, at the national macro-level, cross- national comparisons consistently display a correlation between indicators of social capital and of political engagement, on the one hand, and the size of the third sector, on the other hand. The Nordic countries and Northern European countries are characterized by high levels of social trust and political engagement, while 


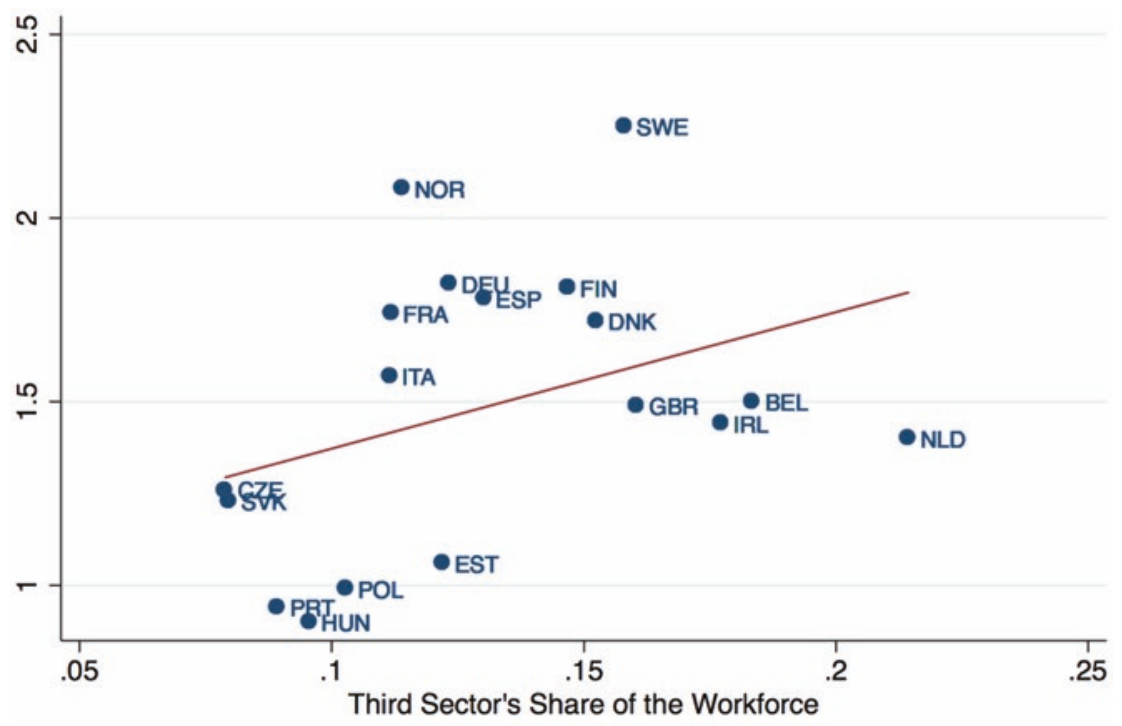

Mean Index Political Engagement

Fitted values

Fig. 4.1 Political engagement by relative size of third sector workforce (20 EU countries)

Eastern European countries display the lowest levels of trust and political engagement and the Southern European countries falling in between these two. High scores on these indicators coincide with vibrant civil societies, absence of corruption, strong trust in institutions, high scores on all indices of economic and gender equality and a culture of adherence to laws and regulations alongside a critical attitude toward politicians and excessive state power.

Robert Putnam's empirical work on Italy suggests that a vibrant civil society sector causes elevated levels of trust in a society (Putnam 1993). But to what extent is the result replicated in other countries?

Interestingly, research at the individual level investigating whether individuals who participate as volunteers in TSOs have higher levels of social trust and political engagement than those who do not volunteer has shown that, when corrected for potential self-selection effects, there is little evidence of such an effect, at least so far as the level of social trust 


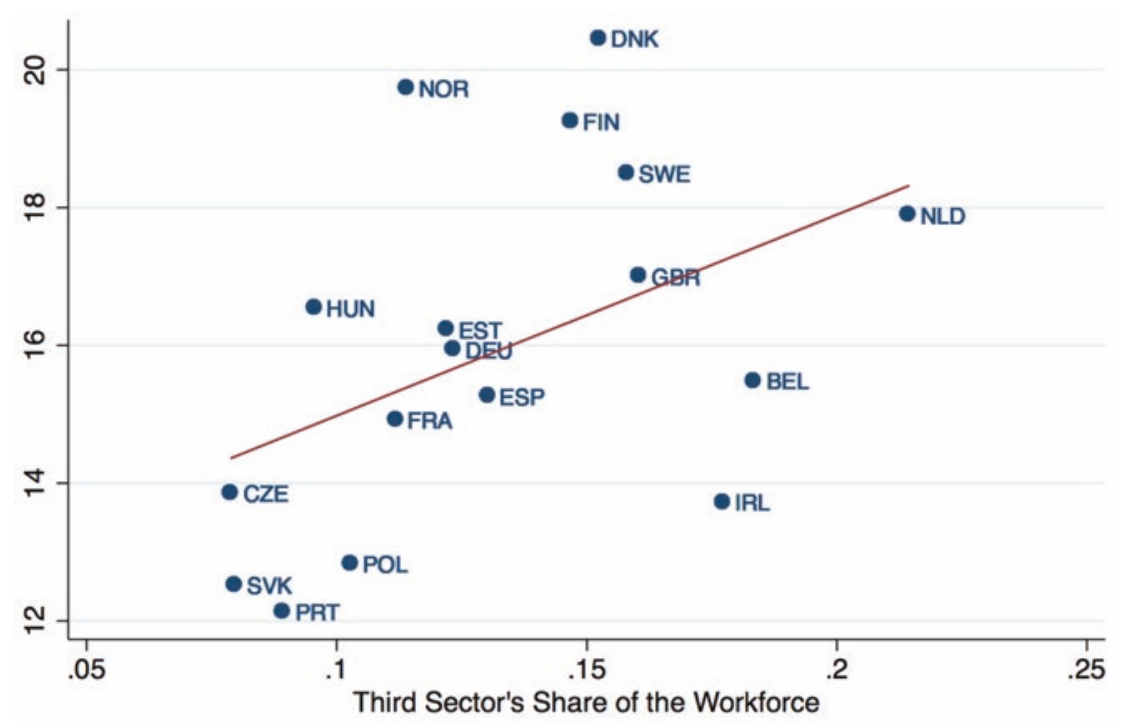

- Mean Social Trust Index — Fitted values

Fig. 4.2 Social trust by the relative size of the third sector workforce (20 EU countries)

is concerned (Claibourn and Martin 2000; Freitag 2003; Enjolras 2015a, b). At the very least, there is little uniformity in this relationship among nations.

Instead of the third sector, other studies attribute high levels of trust to the role played by the welfare state and redistribution. While some authors emphasize lack of social inequality (Bjørnskov 2006; Delhey and Newton 2005; Uslaner 2003), others view institutions of the (welfare) state or the rule of law as the crucial force fostering generalized trust in society (Rothstein 2001). Rothstein and Stolle (2008) have, for example, argued that the welfare state has a particular role in generating trust by sustaining values such as impartiality, equality before the law, respect for human rights, equality of opportunity and efficiency. According to these authors, it is the quality of policy implementation and service delivery by the welfare state that has the strongest bearing on generating trust among citizens. On this account, the role of the third sector in enhancing trust is secondary in comparison to the role of the state. 
A third explanation of the results portrayed in Figs. 4.1 and 4.2, and one favored here, emphasizes the societal externalities created by dense networks of TSOs, producing impacts that extend beyond the members and volunteers of the individual TSOs, through the production of nonexcludable benefits and resources to broader groups of people. In other words, at the societal (macro) level, participation in TSOs is associated with a set of "emergent" properties (Kawashi and Berkman 2014) that are inherent in the social structure and networks generated by the existence of dense networks of TSOs. In other words, this means that, at the societal level, a high density of TSOs enhances a structure of social interactions that is qualitatively different from the one enhanced by a low density of TSOs. Three macro-level mechanisms may help to explain such effects: (1) social contagion, (2) informal social control and (3) collective efficacy.

Social contagion refers to the fact that behaviors spread more quickly through a tightly knit social network. Behaviors can spread in a network through the diffusion of information or through the transmission of behavioral norms. The social networks constituted by a dense third sector are expected to enhance norms and behaviors that are central to TSOs and volunteering, such as trust and civic and political engagement.

Informal social control refers to the ability of individuals in a community to maintain social order, that is, to step in and intervene when they witness deviant behavior by others. The likelihood of informal policing increases with the degree of cohesion of the community, that is, the degree to which its members are socially connected to each other. A high density of TSOs is expected to entail more cohesive social networks and, consequently, a higher likelihood for informal social control, impacting on trust, health-related behavior and civic behaviors.

Collective efficacy is the group-level analog of the concept of selfefficacy, that is, it refers to the ability of a collective to mobilize to undertake collective action. When individuals are connected to each other through TSOs, mobilizing is made easier and free riding more difficult inasmuch as it risks damage to one's reputation as well as provokes social sanctions (i.e. ostracism). Additionally, individuals who are not members of a TSO but are connected through social networks to its members will be able to draw upon the organizational infrastructure and capacity 


\begin{tabular}{|l|l|l|l|}
\hline $\begin{array}{l}\text { Salience of } \\
\text { Third Sector } \\
\text { organizations } \\
\text { in society } \\
\text { measured by } \\
\text { TS share of } \\
\text { workforce }\end{array}$ \\
\end{tabular}$\quad \begin{aligned} & \begin{array}{l}\text { "Emergent" } \\
\text { properties at the } \\
\text { macro level } \\
\text { (1) social contagion } \\
\text { (2) informal social } \\
\text { control } \\
\text { (3) collective efficacy }\end{array} \\
& \text { (n) }\end{aligned}$

Fig. 4.3 Macro impact explanatory model

already established by the organization. Collective efficacy may be a significant factor influencing political engagement (Bandura 2000).

The density of the third sector at the societal level, measured by the third sector workforce (both volunteers and paid workers) is seen as generating macro-level socioeconomic impacts, by the play of emergent properties, according to the explanatory model displayed in Fig. 4.3.

A way to identify a potential socioeconomic impact, mediated by emergent properties, of the third sector at the macro level consists in assessing whether the size of the third sector, measured in terms of its workforce's share in the total workforce of the country, is positively associated with the aggregated indicators of social trust and political engagement, when controlling for other aggregated measures that can influence these indicators, such as the GDP per capita, the level of inequalities measured by the GINI index, the level of social expenditures in the country and the employment rate in the country. The results of the linear regressions of the indicators of trust and political engagement in relation to the size of the voluntary sector (share of the third sector' workforce in the total workforce) and the other control variables are presented in Table 4.1.

The empirical analysis investigates whether the size of the third sector approximated by the share of the third sector workforce (including paid and volunteer work) in the total workforce of the country is associated with social trust, self-reported health, happiness and political engagement. The analyses are based on data for 20 countries (European Union countries : Belgium, Czech Republic, Denmark, Estonia, Finland, France, Germany, Hungary, 
Table 4.1 Linear regression of social trust index, political engagement index, selfreported well-being and self- reported health by country

\begin{tabular}{lllll}
\hline & \multicolumn{2}{c}{ Social trust } & \multicolumn{2}{c}{ Political Engagement } \\
\cline { 2 - 5 } & Model 1 & Model 2 & Model 1 & Model 2 \\
\hline Employment rate & $.127 * * *$ & $.125 * * *$ & $.008 * * *$ & $.009 * * *$ \\
GDP per Capita & $.005^{* * *}$ & $.000 * * *$ & $.000 * * *$ & $.000 * * *$ \\
Gini Index & $-3.766 * * *$ & $-3.941 * * *$ & $1.564 * * *$ & $1.570 * * *$ \\
Social Expenditures & $.116 * * *$ & $.105 * * *$ & $.032 * * *$ & $.035 * * *$ \\
TS share of Workforce & - & $7.590 * * *$ & - & $-2.046 * * *$ \\
Constant & $2.727 * * *$ & $2.681 * * *$ & $-1.203 * * *$ & $-1.187 * * *$ \\
$R$-squared & .480 & .489 & .721 & .747 \\
Change in $R$-squared & - & .009 & - & .026 \\
\hline
\end{tabular}

${ }^{*} p>0.10, * * p>=0.05, * * * p>0.001$

Ireland, Italy, Lithuania, the Netherlands, Poland, Portugal, Slovakia, Spain, Sweden, the UK and non-European Union country: Norway).

For each country, the dependent variables are the means of self-reported indices of health, subjective well-being political engagement and social trust. The means are calculated using the European Social Survey data (European Social Survey, 2012) consisting of a representative sample of the population including all persons aged 15 and over resident within private households, regardless of their nationality, citizenship, language or legal status. The data relative to the independent variables have two origins. The data concerning the third sector's share of the total workforce are provided by Salamon and Sokolowski (2016), whereas the other macro indicators were extracted from the OECD (2012) database.

For each dependent variable (social trust and political engagement), two models are displayed: model 1 shows the association of the dependent variable with a set of independent variables (employment rate, GDP per capita, Gini index as indicator for inequalities, and social expenditures) excluding the third sector share of the workforce, whereas model 2 includes this last variable. Introducing the third sector share of the workforce improves the goodness of fit of the model (R-squared) and shows the contribution of the third sector to social trust and political engagement.

The size of the third sector is heavily positively associated with the level of social trust. Social trust is also negatively associated with the degree of inequalities (GINI index). Even if a simple linear regression is not sufficient for inferring a causal relation between third sector size and social 
trust, and if the possibility of reverse causation cannot not be excluded, the data supports our explanatory model when it comes to social trust, in spite of a contribution to R-squared being weak. At the same time, the added explanatory power attributable to the third sector is quite small, suggesting that the other factors in the model carry most of the explanatory power.

The size of the voluntary sector is negatively associated with the level of political engagement, and political engagement seems to increase when the level of inequality is higher. This reflects the fact that, with the exception of Sweden, the countries with the highest levels of political engagement are not the ones having the biggest third sector.

The potential macro socioeconomic impact of the degree of development of the third sector in different European countries has been conceptualized as the result of emergent macro-level properties linked to the social structure (social networks) generated by TSOs and their activities. From this viewpoint, the more developed the third sector, the greater are its emergent properties at the macro level and the higher its impact. While at the individual level (Enjolras 2015a, b), when correcting for potential selection effects, there is no evidence that active volunteering in TSOs has a positive impact on individual social trust, a simple test of this impact model at the aggregated level_-looking at the associations between the size of the third sector in 20 European countries and social trust and political engagement - shows some support for the existence of an impact of the size of the third sector on social trust.

\subsection{Impact on Well-being and Quality of Life}

A second range of potential impacts of the third sector relate to citizen well-being and quality of life. TSOs have long been associated with the provision of human services that contribute to wellbeing and the quality of life. In fact, this role of the sector is a principal focus of what has long been the dominant economic theory of the third sector, which views the existence of this sector as resulting from a demand for services that neither the market nor government can provide due to inherent failures of these alternative institutions - that is, the "free rider" problem in the case of markets and the need for majority support in the case of governments (Hansmann 1980; Weisbrod 1977). The Stiglitz report emphasized the 


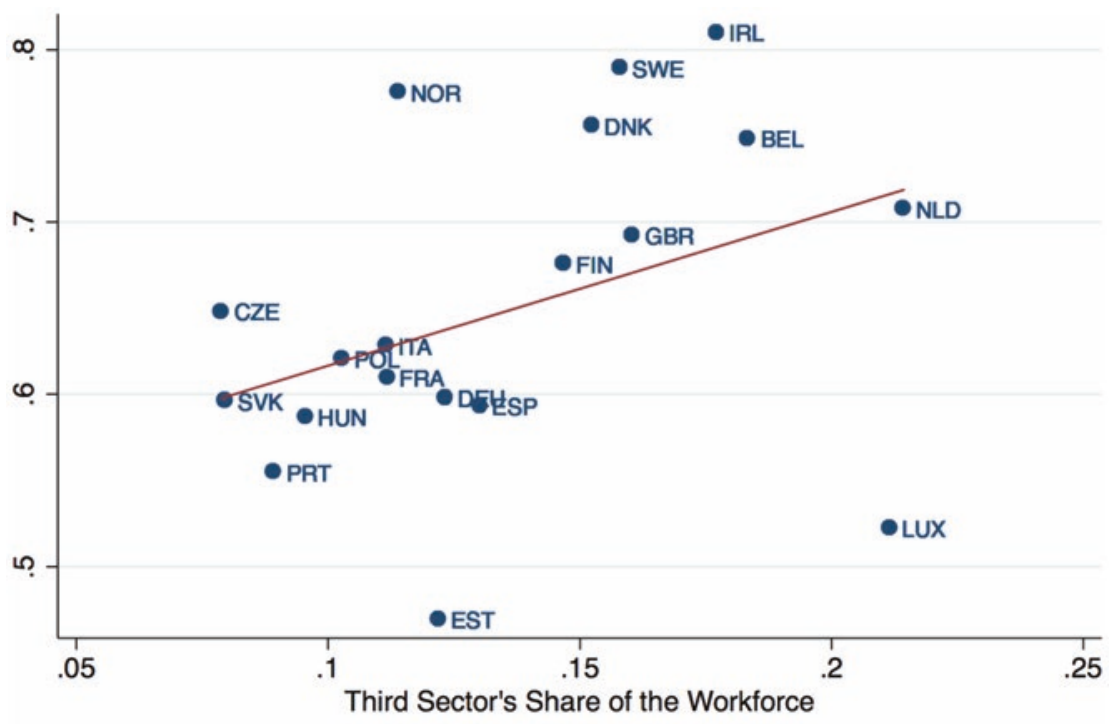

Mean Self-Reported Good Health

Fitted values

Fig. 4.4 Self-reported health by relative size of third sector workforce (20 EU countries)

need to "shift emphasis from measuring economic production to measuring people's wellbeing," (Stiglitz et al. 2009). But well-being involves more than concrete services. It also includes subjective factors, such as feelings of security, sense of well-being, confidence and a sense of belonging (Cummins 2000), all of which have also been associated with TSOs.

As shown in Figs. 4.4 and 4.5, at the societal level, cross-national comparisons consistently display a correlation between indicators of health and wellbeing, on the one hand, and the size of the third sector, on the other hand. ${ }^{2}$

As we did with the socioeconomic indicators of trust and political engagement, we can identify the socioeconomic impact of the third sec-

\footnotetext{
${ }^{2}$ The analyses are based on European Social Survey (2012) data for 20 countries. The self-reported health indicator is based on the questions: "How is your health in general?"- "very good, good, fair, not very good, poor." The subjective well-being indicator used in the analyses is a measure of people's evaluations of their lives as a whole, elicited by a widely used generalized single-item question: "All things considered, how satisfied are you with your life as a whole these days?" on a scale from 1 being completely dissatisfied to 10 being completely satisfied.
} 


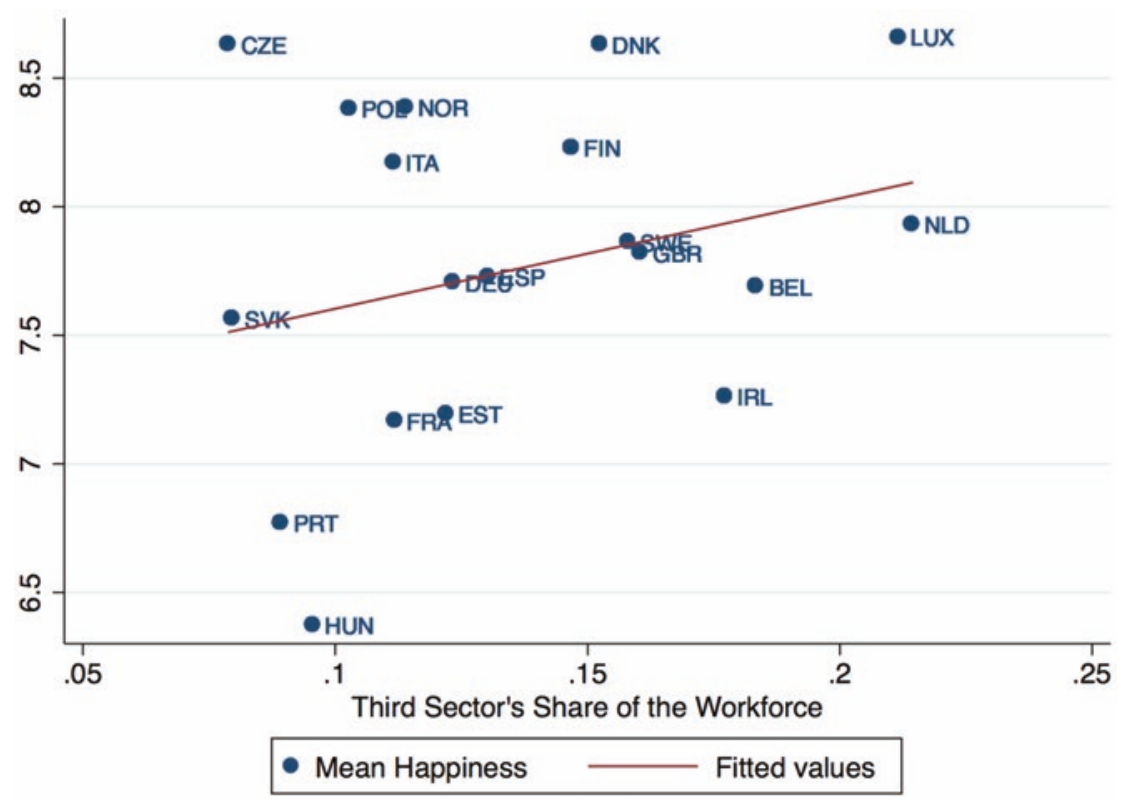

Fig. 4.5 Self-reported wellbeing by third sector workforce (20 EU countries)

Table 4.2 Linear regression of self-reported well-being and self-reported health by country

\begin{tabular}{lllll}
\hline & \multicolumn{2}{l}{ Well-being } & Health \\
\cline { 2 - 5 } & Model 1 & Model 2 & Model 1 & Model 2 \\
\hline Employment rate & $.043^{* * *}$ & $.0442^{* * *}$ & $.000^{* * *}$ & $.000^{* * *}$ \\
GDP per Capita & $.000^{* * *}$ & $.000^{* * *}$ & $.000^{* * *}$ & $-1.56 \mathrm{e}-06^{* * *}$ \\
Gini Index & $-2.315^{* * *}$ & $-2.367^{* * *}$ & $-1.669^{* * *}$ & $-1.654^{* * *}$ \\
Social Expenditures & $-.000^{* * *}$ & $.004^{* * *}$ & $.004^{* * *}$ & $.003^{* * *}$ \\
TS share of Workforce & - & $-2.812^{* * *}$ & - & $.841^{* * *}$ \\
Constant & $5.028^{* * *}$ & $5.064^{* * *}$ & $.995^{* * *}$ & $.984^{* * *}$ \\
$R$-squared & .464 & .481 & .450 & .516 \\
Change in $R$-squared & - & .017 & - & .066 \\
\hline
\end{tabular}

tor at the macro level by assessing whether the size of the third sector (measured in terms of its workforce's share in the total workforce of the country) is positively associated with the aggregated indicators of health and wellbeing. The results of this analysis are presented in Table 4.2. 
The size of the voluntary sector is negatively associated with the level of self-reported well-being after controlling for the other variables that might affect well-being. In addition, levels of well-being decrease with inequalities. At the aggregated level, the size of the third sector is positively associated with self-reported health, though the added explanatory power of this variable is highly limited compared to the other factors identified. In both models, however, the contribution of the third sector share of the workforce (measured by the change in R-squared) is relatively weak, meaning that the explanatory power is being carried mostly by the other variables. Here, too, the macro socioeconomic impact of the third sector on population health in different European countries can be understood as the result of emergent macro-level properties linked to the social structure (social networks) generated by TSOs and their activities.

\subsection{Impact on Human Resources}

Another important perspective on the impacts of the third sector relate to the impacts these organizations have not on the society at large but on those who work in TSOs. This set of impacts has been emphasized most explicitly by students of volunteering, but it also applies to paid personnel. Thus, for example, Rochester et al. (2010) emphasize the benefits accruing to volunteers in terms of increased satisfaction, personal achievement, social networks and relations, skills, personal development, enhanced employability, improved mental and physical health and wellbeing. Similarly, Wilson (2000) identifies four areas where research has pointed to the positive consequences of volunteer work for the volunteer: citizenship (volunteers are more politically active and trusting than nonvolunteers), antisocial behavior (being a volunteer keeps young people out of trouble), health and well-being (volunteers enjoy better health in old age, have better self-esteem and self-confidence and higher levels of life satisfaction) and socioeconomic achievement. Additionally, TSOs offer a space for work integration for individuals excluded from the labor market and provide job experience to young people, to individuals with disability and to the long-term unemployed. Different works have also emphasized the positive impacts accruing to paid staff in TSOs, including higher job sat- 
isfaction because of the higher "pro-social" motivations (Benz 2005; Borzaga and Tortia 2006; Rose-Ackerman 1996) or greater fairness (Leete 2000; Tortia 2008). The literature suggests that people who volunteer enjoy good health (Moen et al. 1993; Musick et al. 1999; Oman et al. 1999; Post, 2005; Brooks 2006). They are also more likely to report being happy and are less likely to suffer from depression (Musick and Wilson 2003; Thoits and Hewitt 2001; Wheeler et al. 1998; Whiteley 2004; Borgonovi 2008). There is also evidence that volunteering positively influences political participation and engagement (Armingeon, 2007).

However, most of the evidence of the positive contribution of volunteering for the volunteers is based on established correlations between volunteering and measures of individual health, well-being or civic engagement. While these correlations are well established, they may be a result of selection bias.

Individuals who already have a greater sense of well-being and better health, higher social trust or levels of political engagement are more likely to be involved in the third sector and are more likely to answer questions about their health and well-being. The positive correlation between volunteering and self-reported health, subjective wellbeing and political participation may therefore be spurious

To address this issue, a study from the Third Sector Impact Project (Enjolras 2015a, b) uses different matching estimation methods (Caliendo and Kopeinig 2008; Guo and Fraser 2015) in order to eliminate the effect of self-selection by constructing a control group that is as similar as possible to the treatment group of interest with respect to observable characteristics. This is done by creating matching estimators by modeling the probability of participating in the treatment given the observed characteristics of the participants in the "treatment group." Volunteers are then matched on the basis of this probability to nonvolunteers in order to compare a "treatment group" (the participants) to a "control group" (the nonparticipants), ensuring that the members of both groups have the same socioeconomic characteristics (based on the variables used to estimate the probability of participation in those groups). The average treatment effect is then the mean difference in outcomes across these two groups. The results, based on the European Social Survey data for 23 European countries, show that volunteering has a minimal impact on 
self-reported health, no impact on self-reported wellbeing, but a significant impact on political engagement (Enjolras 2015a, b).

Another study from the Third Sector Impact Project (Kamerāde and Bennett 2015) focuses on voluntary work during unemployment. It investigates whether volunteering can compensate for the loss in manifest and latent benefits associated with paid work and thus improve unemployed individuals' well-being and mental health. Drawing on data from 29 European countries, and using matching estimators, this study concludes that the impact of volunteering on unemployed individuals' wellbeing and mental health depends on generous welfare benefits. The positive effects of volunteering during unemployment are not unconditional. Theuy obtain when some environmental conditions relative to the level income of unemployed volunnteers are met. In other words, volunteering may improve well-being and health if basic needs are met, but does not compensate for the lack of satisfaction of these basic needs.

The two surveyed analyses show that neither for people in general, nor for more marginalized groups like unemployed individuals, volunteering by itself does not significantly improve health and well-being when measured at the individual level. However, we do not presently know enough about the potential benefits of volunteering for different groups in the population, and the effect may vary with the type of organization, the tasks performed, the number of hours volunteered and the frequency of volunteering. Only a few community studies make it possible to analyze some of these variables.

\subsection{Impact on Social Innovation}

While the economic theories assign a primary role to the state and the market and view the third sector as merely a supplement to these other two sectors, filling in services that the other two sectors fail to supply, a second body of literature views the third sector as a source of pioneering social innovations that government and the market subsequently copy or support. This view has been conceptually articulated most fully in the notion of "interdependence" between the government and the third sector. Because of the transaction costs involved in mobilizing governments 
to act and the free rider problems that keep market actors from responding to many social and economic problems, it is TSOs that frequently come forward to identify unattended problems and devise innovative solutions to them (Salamon 1987, 1996). Social economy literature has also stressed this role of third sector entities, in their case, mutuals, cooperatives and social enterprises, as significant sources of social innovation and social change, contributing to labor market integration, fighting social exclusion and poverty, creating social capital and developing new services and ways to address unmet social need (Chaves and Monzón 2012; J. Defourny and Develtere 1999; Julià and Chaves 2012; Nicholls 2004). TSOs are spaces of freedom and unforced activities where volunteers and professionals in partnership with other stakeholders are in position to respond creatively to new challenges, to develop new forms of organization and interactions and to respond to social demands that are traditionally not addressed by the market or existing institutions. Indeed, TSOs are in a position to generate both types of social innovations that Greffe (2003) identifies_macro-social innovations such as new forms of social organization or networked approaches to addressing public problems, as well as micro-social innovations such as new services that the market does not supply, as well as attention to economic or social values that market production fails to advantage (such as social integration, wellbeing, sustainable development).

The potential contribution of third sector and volunteering to social innovations can be seen on different levels. At the micro level, they can be an important element affecting the socioeconomic development of societies by helping individuals in need, enhancing their capabilities and promoting well-being. Changing the form of governance, as well as the development of local communities, can be distinctive impacts of third sector social innovations on the meso-level. Social innovations at the macro level can involve transforming the ways in which society thinks and acts. Building new social relations can also be a main component of the macro-level impact of third sector social innovations. However, evidence demonstrating the TSI on social innovation remains quite limited (Bežovan 2016). Fortunately, some further research supported by the FP7 project is actively exploring this topic. ${ }^{3}$

${ }^{3}$ Such as EFESEIIS (http://www.fp7-efeseiis.eu) and ITSSOIN (http://itssoin.eu) 


\section{Can the TSE Sector Expand Civil Liberties and the Public Sphere?}

The socioeconomic impacts of TSOs are contingent on the political and institutional context in which the third sector is embedded. Path dependency and social origins theories address both the nature of the civil society regime in which these organizations operate and the institutional space of freedom that the state grants to these organizations. Both the type of civil society regime and the space of freedom are determined by the state of identifiable power relationships among key social groupings during turning points in the historical evolution of societies (Salamon et al. 2017). These appear as crucial factors influencing the type and degree of impact that the TSE sector can make on society.

This chapter started by defining some areas where potential impacts of the TSE sector may be observed. Some of the most important impacts are related to the civil society role of TSOs in linking citizens and the policymaking processes; this role is among the most distinctive roles of the TSE sector that cannot be substituted by the other sectors of society-corporations, government or households. However, it is also very difficult to measure this kind of impact. The best option is to observe changes in the civil society role over time and what effects this may have on democracy and civil liberties over time, or, even better, to compare the development in countries with some important common historical characteristics to see what policies and structures may inhibit or promote the civil society role of the TSE sector.

A third sector impact project's study of civil liberties and volunteering in six former Soviet bloc countries examines whether volunteering is an outcome of democratization rather than a driver of it. It analyzes how divergent democratization pathways in six countries of the former Soviet Union have led to varied levels of volunteering, using data from the European Values Study.

The results show that Latvia, Lithuania, and Estonia-which followed a path toward EU accession-have high and increasing levels of civil liberties and volunteering. In Russia and Belarus, following another path, civil liberties have remained low and volunteering has declined. Surprisingly, despite the Orange Revolution and increased civil liberties, 
volunteering rates in Ukraine have also declined. The case of Ukraine indicates that the freedom to participate is not always taken up by citizens. The findings suggest it is not volunteering that brings civil liberties, but rather that increased civil liberties lead to higher levels of volunteering (Kamerāde et al. 2016), a finding that is consistent with the social origins theory contention that patterns of power shape the space for civil society development and hence the scope and scale of civil society organization development (Salamon et al. 2017).

Another historical and comparative study examines the role and impact of the third sector in the transformative processes of post-socialist countries by comparing Slovenia, the Czech Republic and Croatia, showing different paths for the third sector depending on the role played by the state (Bežovan 2016).

From the very beginning, civil society initiatives played an important role in the changes that occurred in post-socialist countries like the Czech Republic, Slovenia and Croatia. They were, in different ways, initiators of changes in the late 1980s and an active part of the new overall agenda on development in the 1990s and onwards.

It is interesting to compare these countries because there are important similarities in their historic background. Before World War I, they were all part of the Austro-Hungarian Empire, which was relatively liberal regarding the expression of the major nationalities and languages. This also meant that there was a high level of popular participation in the cultural sphere in these countries. During the communist era, civil liberties were repressed and there were confrontations between civil society in different forms and the authoritarian regime. Dissidents, often with support from the west, focused on promoting human rights and political pluralism. A multi-party system and parliamentarian democracy were almost synonymous with the concept of civil society. During the 1990s, there were frequent confrontations with the authoritarian regime in Croatia, while in Slovenia, there was more dialogue, as independent intellectuals and civic movements with younger participants played the role of setting up political parties (Bežovan 2004). However, there were different political understandings of the role of civil society. In Czechoslovakia, President Vaclav Havel saw civil society and public debate as essential for the creation of good citizens, and promoted decentralization of state responsibilities. 
After the split into the two sovereign states in 1993, Vaclav Klaus, president of the Czech Republic, had different views. He supported the introduction of a competitive party system, but saw the market as the central instrument to promote human freedom and creativity. He was very suspicious of the term civil society and preferred the indirect participation of citizens rather than giving nonprofit organizations a privileged role as mediators between citizens and the government. These different views became paradigmatic for the development of civil society in the advanced Central Eastern European countries.

In political debates, civil society was often recognized as a revolutionary force and as part of the opposition. NGOs were under political attack from the ruling parties and governmental organizations, and there was no support for tax incentives or increased organizational participation in policymaking. They have even been accused of being agents of foreign powers or officially characterized as a "self-proclaimed civil society" (Bežovan 2004). On the other hand, there was a "parochial" structure of organizations often divided on the same issues as political parties, and often seen as mostly interested in securing government and other grants. The concept of civil society was associated with a struggle against the ruling regime and the dominant political culture, in which the old Soviet era mass organizations (related to the Communist party) were an integral part.

However, the process toward EU accession was important for strengthening the legitimacy of the civil society organizations and giving them a role as stakeholders in policymaking and policy implementation (Frič 2009). Crucial influences in the recent development of the sector came from the EU in the form of membership, financial support and technical help.

In the last 25 years, it is evident that civil society has become a respected stakeholder in all three countries, with certain differences that can be attributed to path dependency, the role of international donors, and the speed of accession to the EU. Thus, for example, in the 1990s, the countries were in different positions in relation to the dissolution of the former states of Yugoslavia and Czechoslovakia. Croatian and to a lesser extent Slovenian development was marked by the Balkan war, which made a long-lasting impact on society. The legacy of dissident culture and 
the financial aid of foreign donors increased the gap between citizens and civil society organizations in the Czech Republic and Croatia. Civil society is weak in engaging citizens in the Czech Republic and Croatia, while civil society appears to enjoy more space and legitimacy in corporatist Slovenia.

This comparison shows that the impact of TSOs depends on the policy environment for the third sector, political openness of the government for cooperation, and on the capacity developed by the TSOs. The institutional infrastructure for sector's development (resource centers, funding programs, pilot projects) is important for sustainable development and for innovative third sector practices (Bežovan 2016).

\section{Does the European Third Sector make a Socioeconomic Impact?}

The previous chapter shows that the TSE organizations and volunteers are a significant economic sector of activity in Europe. In this chapter, we have assessed the available evidence about the contribution of this TSE sector to the socioeconomic development and democratic governance of European societies through systematic reviews of research and new analyses of data. This indicates that the impact of the TSE sector is significant albeit difficult to assess empirically. This is because the activities of organizations and volunteers can have impacts in different social domains and on different levels, from individuals to local communities and society in general, and the research front is less advanced in some of these areas than others are. However, there is no support for unconditional and general claims about the third sector's contribution to improvement of health, well-being, innovation, social capital, empowerment or economic development.

There is a potential for individual benefits of membership or volunteering in TSOs. However, these positive impacts are not equally accessible or do not spread among the population. Individuals who already have better wellbeing, health and social trust are more likely to be active as members or volunteers in the third sector. Groups and individuals with fewer resources or who are already less advantaged are less likely to become 
members or volunteers in voluntary organizations to promote their interests, satisfy their needs or make changes in policy favorable to them. This seriously complicates the task of sorting out cause and effect. Moreover, the effects of voluntary participation are gendered and can also vary by age, employment status, income, type of association and type of involvement (Kamerāde 2015). In short, third sector activity is not a simple solution to individual or social problems. Those that have the largest potential benefits from TSIs are less likely to be involved, which represents a challenge for how to design third sector activities and support programs (Kamerāde 2015).

Our research shows that better health and well-being may be a result of who decides to volunteer, rather than an effect of volunteering for the general population. However, political engagement may increase as a result of volunteering. Among the unemployed, volunteering may improve mental health and well-being, but only when there are generous welfare benefits. These findings indicate that the impacts of the third sector depend not only on the activities that take place, but also on the kind of support and conditions the governments provide.

At the macro level, assessing the socioeconomic impact of the third sector confronts much of the same difficulties encountered at the micro level. In the absence of a unified data collection apparatus on the third sector at the European level, reliable longitudinal data on the third sector are difficult to obtain. Methodologically, the same difficulties related to identifying a causal link between a given feature of the third sector and expected impacts apply, given the potential existence of confounding factors not accounted for in the statistical models. Additionally, when aggregating individual behaviors at the macro-level, potential emergent properties - such as social contagion, informal social control and collective efficacy - that may lead to divergent results at the micro and macro levels, have to be taken into account. Our results show that participating in volunteering activities does not have an impact on individual wellbeing, health and level of social trust when correcting for potential selfselection. However, that does not mean that the same pattern applies at the macro level. Indeed, the size of the third sector seems to be positively correlated with social trust and health. This is in line with the assumption that the third sector is important as an infrastructure, even in areas where 
individual experience with volunteering does not have an effect. A vital civil society can contribute to breaking the vicious circle of distrust, corruption and bad government because people see that there are organizational structures they can work through to promote change.

When we compare the role of the third sector in the transformation of the post-communist countries during the last 25 years in Slovenia, the Czech Republic and Croatia, we also see the importance of the relations with the government. In all three countries, the TSOs have tried to play a civil society role, expand the public sphere, and promote civic liberties. However, there are significant differences in how they succeeded depending on what the social origins theory would suggest are the prevailing structures of power and the resulting institutional infrastructure enabling citizens to work for changes in policies. This, in turn, depends on previous history, but also on the present political circumstances.

Knowledge about the impacts of the third sector on other parts of society is scattered and inconclusive. Measurement of the third sector's size, structure and composition can take advantage of standardized procedures, definitions and typologies, such as the ILO Manual on the Measurement of Volunteer Work ${ }^{4}$, and the UN Handbook on Nonprofit Organizations in the System of National Accounts', soon to be issued in a revised, expanded version that covers the third sector as conceptualized in this report. Most important for this present chapter, the resulting newly revised UN handbook, entitled Satellite Account on Nonprofit and Related Institutions and Volunteer Work, contains a new chapter that lays out a comprehensive strategy keyed to the new UN Sustainable Development Goals for measuring systematically and comparatively the impact of the TSE sector on the achievement of these goals. Unfortunately, these procedures are not fully implemented across Europe, a consequence being the poor quality of available data about the third sector and volunteering. Whereas a theoretical understanding of the functions, roles and specific features of TSOs points in the direction of a wide array of potential socio-

\footnotetext{
${ }^{4}$ Manual on the Measurement of Volunteer Work, International Labour Organization 2011 (ILO Manual).

${ }^{5}$ UN Handbook on Nonprofit Institutions in the System of National Accounts, 2003 (UN Handbook).
} 
economic impacts at different levels of analysis, the scarcity and limited quality of the available data means that the empirical validation of these theoretical insights is only possible to a limited extent. Research on the impact of the third sector is in an early phase, and we need to further develop impact indicators and methods that can reliably identify causal links between third sector activities and micro and macro impacts. Hopefully, as the new UN TSE Satellite Account document comes online, countries, with the encouragement of the European Commission and Eurostat, will take measures to implement it across Europe.

\section{References}

Almond, G. A., \& Verba, S. (1963). The civic culture: Political attitudes and democracy in five nations. Boston: Little, Brown and Company.

Armingeon, K. (2007). Political participation and associational involvement. In J. W. van Depth, J. R. Montero, \& A. Westhilm (Eds.), Citizenship and involvement in European democracies. London: Routledge.

Bandura, A. (2000). Exercise of human agency through collective efficacy. Current Directions in Psychological Science, 9(3), 75-78.

Benz, M. (2005). Not for the profit, but for the satisfaction? Evidence on worker well-being in non-profit firms. Kyklos, 58(2), 155-176.

Bežovan, G. (2004). Civilno društvo. Zagreb: Nakladni zavod Globus.

Bežovan, G. (2016). The role and impact of the Third Sector in transformative process: A comparison of post-socialist countries Slovenia, Czech Republic and Croatia. TSI Working Paper Series No. 13, Seventh Framework Programme (grant agreement 613034), European Union. Brussels: Third Sector Impact.

Bjørnskov, C. (2006). Determinants of generalized trust: A cross-country comparison. Public Choice, 130, 1-21.

Borgonovi, F. (2008). Doing well by doing good. The relationship between formal volunteering and self-reported health and happiness. Social Science \& Medicine, 66, 2321-2334.

Borzaga, C., \& Tortia, E. (2006). Worker motivations, job satisfaction, and loyalty in public and nonprofit social services. Nonprofit and Voluntary Sector Quarterly, 35(2), 225-248.

Brooks, A. C. (2006). Who really cares? The surprising truth about compassionate conservatism. New York: Basic Books. 
Caliendo, M., \& Kopeinig, S. (2008). Some practical guidance for the implementation of propensity score matching. Journal of Economic Surveys, 22(1), $31-72$.

Chaves, R., \& Monzón, J. L. (2012). Beyond the crisis: The social economy, prop of a new model of sustainable economic development. Service Business: An international Journal, 6(1), 5-26.

Claibourn, M., \& Martin, P. (2000). Trusting and joining? An empirical test of the reciprocal nature of social capital. Political Behavior, 22(4), 269-291.

Cummins, R. A. (2000). Objective and subjective quality of life: An interactive model. Social Indicators Research, 52, 55-72.

Defourny, J., \& Develtere, P. (1999). Social economy: North and South. In J. Defourny, P. Develtere, \& B. Fonteneau (Eds.), Social economy: The worldwide making of a third sector (pp. 25-56). Brussels: De Boeck.

Delhey, J., \& Newton, K. (2005). Predicting cross-national levels of social trust: Global pattern or Nordic exceptionalism? European Sociological Review, 21(4), 311-328.

Enjolras, B. (2015a). Measuring the impact of the third sector: From concept to metrics. TSI Working Paper No. 5, Seventh Framework Programme (grant agreement 613034), European Union. Brussels: Third Sector Impact.

Enjolras, B. (2015b). The impact of volunteering on volunteers in 23 European countries. Third Sector Working Paper No. 4, Seventh Framework Programme (grant agreement 613034), European Union. Brussels: Third Sector Impact.

European Social Survey. (2012). Retrieved from http://www.europeansocialsurvey.org/data/download.html? $r=6$

Freitag, M. (2003). Social capital in (dis)similar democracies: The development of generalised trust in Japan and Switzerland. Comparative Political Studies, 36(8), 936-966.

Frič, P. (2009). The third sector and the policy process in the Czech Republic: Self-limited dynamics. In J. Kendal (Ed.), Handbook on third sector policy in Europe-multi-level processes and organized civil society (pp. 184-206). Cheltenham: Edward Elgar.

Greffe, X. (2003). Innovation, value added and evaluation in the third system: A European perspective. In The Non-profit Sector in a Changing Economy (pp. 189-220). Paris: OECD.

Guo, S., \& Fraser, M. W. (2015). Propensity score analysis. London: Sage. Habermas, J. (1989). The structural transformation of the public sphere: An inquiry into a category of bourgeois society. Cambridge, MA: MIT Press.

Habermas, J. (1998). Between facts and norms. Cambridge: The MIT Press. 
Hansmann, H. (1980). The role of non profit enterprise. Yale Law Journal, 89(2), 835-898.

Howard, M., \& Gilbert, L. (2008). A cross-national comparison of the internal effect of participation in voluntary organizations. Political Studies, 56, 12-32. International Labour Organization. (2011). Manual on the measurement of volunteer work. Geneva: International Labour Organization.

Julià, J. F., \& Chaves, R. (2012). Introduction: Social economy, a third sector in a plural people- oriented economy. Service Business: An International Journal, 6(1), 1-4.

Kamerāde, D. (2015). Third sector impacts on human resources and community: A critical review. Third Sector Impact Working Paper No. 3, Seventh Framework Programme (grant agreement 613034), European Union. Brussels: Third Sector Impact.

Kamerāde, D., \& Bennett, M. (2015). Unemployment, volunteering, subjective well-being and mental health. TSI Working Paper Series No. 7, Seventh Framework Programme (grant agreement 613034), European Union. Brussels: Third Sector Impact.

Kamerāde, D., Crotty, J., \& Ljubownikow, S. (2016). Civil liberties and volunteering in six former Soviet Union countries. Nonprofit and Voluntary Sector Quarterly, 45(6), 1150-1168. https://doi.org/10.1177/0899764016649689. Kawashi, I., \& Berkman, L. F. (2014). Social capital, social cohesion, and health. In L. F. Berkman, I. Kawachi, \& M. M. Glymour (Eds.), Social epidemiology (pp. 290-319). Oxford: Oxford University Press.

Leete, L. (2000). Wage equity and employee motivation in nonprofit and forprofit organizations. Journal of Economic Behavior \& Organization, 43, 423-446. Moen, P., Dempster-McCain, D., \& Williams, R. M. (1993). Successful aging. American Journal of Sociology, 97, 1612-1632.

Musick, M. A., Herzog, A. R., \& House, J. S. (1999). Volunteering and mortality among older adults: Findings from a national sample. Journals of Gerontology Series B, 54(3), 173-180.

Musick, M. A., \& Wilson, J. (2003). Volunteering and depression: The role of psychological and social resources in different age groups. Social Science \& Medicine, 56, 259-269.

Nicholls, A. (2004). Social entrepreneurship: The emerging landscape. In S. Crainer \& D. Dearlove (Eds.), Financial times handbook of management (3rd ed., pp. 636-643). Prentice Hall/Financial Times.

Nicholls, A., Paton, R., \& Emerson, J. (Eds.). (2010). Social finance. Oxford: Oxford University Press. 
Oman, D., Thoresen, C. E., \& McMahon, K. (1999). Volunteerism and mortality among the community-dwelling elderly. Journal of Health Psychology, 4, 301-316.

Post, S. G. (2005). Altruism, happiness, and health: It's good to be good. International Journal of Behavioral Medicine, 12(2), 66-77.

Putnam, R. D. (1993). Making democracy work: Civic traditions in modern Italy. Princeton, NJ: Princeton University Press.

Putnam, R. D. (2000). Bowling alone. New York: Touchstone.

Rhodes, R. A. W. (1997). Understanding governance: Policy networks, governance, reflexivity, and accountability. Buckingham: Open University Press.

Rochester, C., Ellis Paine, A., Howlett, S., \& Zimmeck, M. (2010). Volunteering and society in the 21st century. Basingstoke: Palgrave Macmillan.

Rose-Ackerman. (1996). Altruism, nonprofits, and economic theory. Journal of Economic Literature, XXXIV, 701-728.

Rothstein, B. (2001). Social capital in the social democratic welfare state. Politics \& Society, 29(2), 207-241.

Rothstein, B., \& Stolle, D. (2008). The state and social capital-An institutional theory of generalized trust. Comparative Politics, 40(4), 441.

Sabatier, P. A. (1998). The advocacy coalition framework: Revisions and relevance for Europe. Journal of European Public Policy, 5(1), 98-130.

Salamon, L. M. (1987). Of market failure, voluntary failure, and third party government: Toward a theory of government -nonprofit relations in the modern welfare state. Journal of Volontary Reaserch, 16, 1.

Salamon, L. M. (1996). Partners in public service: Government-nonprofit relations in the modern welfare state. Baltimore: Johns Hopkins University Press.

Salamon, L. M. (2014a). Leverage for good: An introduction to the new frontiers of philanthropy and social investment. New York: Oxford University Press.

Salamon, L. M. (2014b). The new frontiers of philanthropy: A guide to the new actos and tools reshaping global philanthropy and social investment. Oxford: Oxford University Press.

Salamon, L. M., \& Sokolowski, S. W. (2016). Beyond nonprofits: Reconceptualizing the third sector. Voluntas, 27, 1515-1545.

Salamon, L. M., Sokolowski, S. W., \& Haddock, M. A. (2017). Explaining civil society development: A social origins approach. Baltimore: Johns Hopkins University Press.

Simsa, R., Rausher, O., Schober, C., \& Moder, C. (2014). Methodological guidelines for impact assessment. Third Sector Impact Working Paper No. 1, 
Seventh Framework Programme (grant agreement 613034), European Union. Brussels: Third Sector Impact.

Stiglitz, J. E., Sen, A., \& Fitoussi, J.-P. (2009). Report by the commission on the measurement of economic performance and social progress. Retrieved from www.stiglitz-sen-fitoussi.fr

Thoits, P. A., \& Hewitt, L. N. (2001). Volunteer work and well-being. Journal of Health and Social Behavior, 42(2), 115-131.

Tocqueville, A. (1955/2000). Democracy in America. New York: Vintage Books. Tortia, E. (2008). Worker well-being and perceived fairness: Survey-based findings from Italy. The Journal of Socio-Economics, 37, 2020-2094.

Uslaner, E. M. (2003). Trust, democracy and governance: Can government politics influence generalised trust? New York: Palgrave Macmillan.

Weisbrod, B. A. (1977). The voluntary nonprofit sector. Lexington, MA: D.C. Heath.

Wheeler, J. A., Gorey, K. M., \& Greenblatt, B. (1998). The beneficial effects of volunteering for older volunteers and the people they serve: A meta-analysis. International Journal of Aging and Human Development, 47, 69-79.

Whiteley, P. (2004). The art of happiness: Is volunteering the blueprint for bliss? London: Economic and Social Research Council.

Wilson, J. (2000). Volunteering. Annual Review of Sociology, 26, 215-240.

Open Access This chapter is distributed under the terms of the Creative Commons Attribution 4.0 International License (http://creativecommons.org/ licenses/by/4.0/), which permits use, duplication, adaptation, distribution and reproduction in any medium or format, as long as you give appropriate credit to the original author(s) and the source, a link is provided to the Creative Commons license and any changes made are indicated.

The images or other third party material in this chapter are included in the work's Creative Commons license, unless indicated otherwise in the credit line; if such material is not included in the work's Creative Commons license and the respective action is not permitted by statutory regulation, users will need to obtain permission from the license holder to duplicate, adapt or reproduce the material. 